\title{
The Development and Economic Impact of Cultural Tourism and Sustainable Heritage Management
}

\author{
Z. Rosická* \\ Faculty of Restoration, University of Pardubice, Czech Republic \\ *Corresponding autor: zdena.rosicka@upce.cz \\ D. Bednářová \\ Faculty of Economics, University of South Bohemia in Ceske Budejovice, Czech Republic \\ L. Beneš \\ Jan Perner Transport Faculty, University of Pardubice, Czech Republic
}

\begin{abstract}
Cultural heritage records and expresses the long processes of historic development, it forms the essence of diverse national, indigenous and local identities and it is an integral part of modern life. The dynamic interaction between tourism and cultural heritage continues to be among the foremost vehicles for cultural exchange providing a personal experience from the past, as well as of the contemporary life and society. It is appreciated as a positive force for natural and cultural conservation. Tourism can underline the economic characteristics of the heritage and points out the need for conservation by generating funding, educating the community and influencing policy. The achievement of a beneficial interaction between the conflicting expectations of visitors and the host or local communities presents many challenges and opportunities. The natural and cultural heritage, diversities and living cultures are major tourism attractions.
\end{abstract}

KEY WORDS: Cultural tourism, heritage, environment, management, sustainability.

\section{SUSTAINABLE CULTURAL TOURISM}

The idea of sustainable development is about 20 years old and the concept of sustainable cultural tourism is even younger. No destination or business can be everything to all tourists. Destinations and businesses must make a series of hard decisions about where it is best to allocate limited resources to achieve the best optimum results. No two destinations are the same, and the choices made and the paths taken to sustainability will vary from destination to destination. What does the sustainable tourist development question involve? It has to take into account both economical and ecological concerns. The World Tourist Organization defines sustainable tourism as "tourism which leads to the management of all resources in such a way that economic, social and aesthetic needs can be filled while maintaining cultural integrity, essential ecological processes, biological diversity and life support systems" (Rosicka, 2008). Considering the historical point of view, tourism has often been unsustainable, as it is a strong competitor for resources - the provision of cultural and ecotourism opportunities for tourist may mean that local residents are sometimes displaced. The requirements of tourists are different from those of local 
residents and serving tourists may not always suit the needs of local residents. Tourism is often focused on local communities, in particular, on rural and minority communities at a speed that may cause disruptions. However, sustainable tourism is a hot issue how best to encourage tourism while minimizing its cost. Cultural diversity exists in time and space, and demands respect for other cultures and aspects of their belief systems. In cases where cultural values appear to be in conflict, respect for cultural diversity requires acknowledgement of the legitimacy of the cultural values of all times. The diversity of cultures and heritage is an irreplaceable source of spiritual and intellectual richness for all humankind. The protection and enhancement of cultural and heritage diversity should be promoted as an essential aspect of human development. Tourists are usually fascinated by nature and culture. Visiting natural and cultural heritage sites takes us back to the roots of civilization, we are taught to experience the past and absorb our planet's natural and cultural variety. Biodiversity and ecology are being endangered world-wide. Even the natural sites, like national parks, are under growing pressure caused by the growing number of population, economical growth and uncontrolled tourism development. Many cultural heritage sites also have to tackle adverse impacts of the enormous number of visitors who seek access to them. Sometimes we are focused too much on the negative impacts of tourism on nature and cultural heritage. However, many natural and cultural sites would welcome tourism as a source of much needed income, and it is even a tool for sustainable development involving the local community actively in tourism and in conservation. Cooperation with the tourism industry is no longer a taboo topic. Both tourists and visitors are getting more experienced, and therefore more demanding. They search for and seek new experiences, they try to discover new knowledge horizons and require high level facilities and services. Value for money and quality is the hot issue of the day.

The idea of sustainable tourism has been developed for more than 15 years considering four basic supports, i.e. ecological, economic, culture and community sustainability. Ecological sustainability, being compatible with the maintenance of essential ecological processes, biological diversity and biological resources, specifies local, regional and national tourism policies and development strategies resulting from the objective of sustainable development. An ecological approach establishes guidelines for tourism operations, ensures tourism in protected areas, such as national parks, conducts research on the impacts of tourism, promotes acceptability and responsibility, etc. Economic sustainability should be profitable in both the short and long term horizon. It provides financial incentives for the business to adopt sustainability principles, contributes to the income, it diversifies the products by developing a wide spectrum of tourist activities, and helps to promote an ethical and environmentally conscious behavior among clients. Cultural sustainability should be compatible with the culture and values in question and support the community identity. It is to improve and manage heritage and natural resources, initiate tourism, conserve cultural diversity, guarantee the protection of the countryside, local indigenous cultures and traditional knowledge, encourage the community ability to maintain and use traditional skills and educate tourists about desirable behavior. Community sustainability is designed to benefit local communities, generate income, maintain control over tourism development, encourage businesses to minimize negative effects on local communities, provide quality employment to community residents and improve local human resource capacity. Developing sustainable tourism within heritage sites is a challenging task for site managers that usually have an ecological, historic, art, archeological, biological and other sciences background. It also calls for a pro-active relationship with communities and regions that find themselves within the site proximity; it fits well into new management approaches for heritage sites. Integrated management of natural and cultural heritage sites deals with the sustainable use of natural and cultural resources targeted both at conservation and development goals. 
It draws particular attention to the communities that live in and around natural and cultural heritage sites and tries to improve the quality of life in those communities. It results from cooperation with other stakeholders, such as tourism industry, travel agencies and various non-government and government organizations.

\section{HERITAGE SITE MANAGEMENT}

Management of heritage sites has undergone crucial and remarkable changes over the last decades. The level of professional know-how and skills has been rising. Heritage sites and areas are no longer characterized as protected territories, which have to be defended and protected against the outer world. Heritage management used to be the sphere of interest of scientists devoted to their surrounding world. Fortunately, heritage is being accepted and perceived as a value, which can only survive under a pro-active management. Effective protection and restoration of natural and cultural heritage has to be based on adapting to a continuously changing environment. Urban planning departments, real estate developers are seen as potential allies not a potential threat. Therefore sustainable tourism could be one of those allies as well. Heritage management is a managerial approach for heritage sites, resulting from a new philosophy. It integrates the site with its environment, its stakeholders and visitors. The approach and perception of the visitors is changing as well. They are no longer just subjects of education, objects of sharing information and targets of applied regulations and rules. Tourism marketing is gradually accepted as a tool for delivering services and products to specific target groups of population. Local, regional and national institutions are focusing more on the benefits of tourism development for conservation and economic goals. Tourist consumers are becoming more demanding, sophisticated and making ethical choices. Cultural assets are one of a few unique features of regions providing a highly competitive advantage. However, there are problems resulting from transition from a demand to a market economy in some countries. Unfortunately, various new destinations promote sustainability and at the same time follow negative old practices that had been troubling the tourism domain before. Theory and practice are often on the opposite banks of the river and we may just hope in narrowing the flowing river or finding a ford at least. Large scale mass tourism is pursued because of the foreign direct investment and foreign exchange it generates. It attracts foreign aid for large scale infrastructure development, improving the economic well-being of residents through economic growth and job creation; it also supports a conservation priority. There are many tourism products to be offered: ethical and sustainable high quality products and services benefiting local communities. Services should be targeted at educated tourists willing to find special interest destinations where tourist industry and host communities are able to cooperate profitably.

\section{CULTURAL TOURISM CHARTER}

ICOMOS, the International Council on Monuments and Sites, adopted the International Cultural Tourism Charter at the $12^{\text {th }}$ General Assembly in Mexico, October 1999. The Charter seeks to encourage a wide public appreciation of cultural heritage sites as centers of learning and reflection about the past, as well as vital local resources for sustainable community development. Cultural traditions and local historical perceptions are part of a site's significance and interpretation should recognize and respect the coexistance of scientific and cultural values as they can enrich the visitor's appreciation of the site. On one hand, conservation should provide responsible and well-managed opportunities for members of the host community and visitors to experience and understand the community heritage 
and culture, and on the other hand, domestic and international tourism can be characterized as an efficient means for cultural exchange. Heritage includes the natural as well as cultural environment, and it covers landscapes, historic places, sites, built environments, biodiversity collections, past and continuing cultural practices, living experience and knowledge. It records the long processes of historic development. The natural and cultural heritage is a material and spiritual resource, which provides a narrative of historical development. Programs for the protection and conservation of the physical attributes, contemporary cultural expressions should facilitate the appreciation and understanding of the significance of heritage by the host community and the visitor. The long-term protection and conservation of living cultures, heritage places, collections, their physical and ecological integrity and environmental background should be a crucial component of economic, social, political, cultural and tourism development policies. Before heritage places are promoted or developed for increased tourism, management plans should assess the natural and cultural values of the resource. They should establish appropriate limits of acceptable change, particularly in relation to the impact of visitor numbers on the physical characteristics, integrity, ecology and biodiversity of the place, transportation systems, social and economical well-being of the host community. Respect for the sanctity of spiritual places and traditions are an important consideration for site managers, visitors, planners and tourism operators. Visitors should be encouraged to behave as welcomed guests, respecting values and lifestyles of the host community and conducting themselves in a responsible manner which would generate a renewed welcome.

\section{CONCLUSION}

Conservation management and tourism activities should provide equitable economic, cultural and social benefits to people of the host or local community at all levels via education, training and the creation of full-time employment opportunities. Heritage interpretation and education programs among the people of the host community should encourage the involvement of local site interpreters. Places and collections of heritage significance should be promoted and managed in ways which protect their authenticity and enhance the visitors' experience. In case the heritage of any specific place may have a universal dimension, the needs and wishes of some communities to restrict or manage physical, spiritual or intellectual access to certain cultural practices, knowledge artifacts or sites should be respected.

\section{ACKNOWLEDGMENT}

This paper has been supported by the University of Pardubice; it is the result of cooperation between the Faculty of Restoration and Jan Perner Transport Faculty.

\section{REFERENCES}

BENES, L., FLEISSIG, P., ROSICKA, Z.: Vita in societate secura, Pardubice 2008, Univerzita Pardubice, Dopravní fakulta Jana Pernera, ISBN 978-80-7395-117-7.

ROSICKA, Z.: Emergency preparedness related to cultural heritage, Pardubice 2008, Institut Jana Pernera, ISBN 978-80-86530-44-4.

International Charter on Cultural Tourism, 1999, ICOMOS. 